\title{
Survey of Therapeutic Drug Monitoring Practices in Pediatric Health Care Programs across Canada
}

\author{
Donna Leung, Mary H H Ensom, and Roxane Carr
}

\begin{abstract}
Background: Therapeutic drug monitoring (TDM) is helpful in situations where a drug has a narrow therapeutic index, a drug dosage does not reliably predict serum concentration, or a serum drug concentration has surrogate value (i.e., is reflective of clinical outcomes). TDM is especially important for the pediatric population, where wide variability in pharmacokinetics and differences in body composition and drug disposition exist. Unfortunately, very little is known about pediatric TDM patterns and the factors that affect the ordering of serum drug measurements.
\end{abstract}

Objectives: To describe TDM practice for pediatric patients in Canada, to report on the drugs that are monitored and how they are monitored, and to discern factors that influence pediatric TDM patterns.

Methods: An electronic survey was developed with online survey software and was disseminated to 42 pediatric health care centres in Canada over the period January to March 2016.

Results: Of the 42 sites invited to participate in the survey, 20 (48\%) responded. All sites reported performing TDM for pediatric patients, and the median number of drugs monitored was 18.5 (range 9-28) per site. The sites differed in terms of TDM practice (e.g., indications for TDM, types of serum drug measurements). Pharmacogenetic testing currently does not play a major role in TDM. Reported barriers to TDM practice include perceived lack of clinical value for certain drugs, limited access to analytical testing, and delayed return of test results.

Conclusions: TDM practice is widespread in Canada. To better utilize TDM for clinical practice, future efforts can be aimed toward increasing awareness of the clinical value of TDM and improving the timeliness of access to TDM results.

Keywords: therapeutic drug monitoring, pediatric, survey, Canada, hospital

Can J Hosp Pharm. 2019;72(2):126-32

\section{RÉSUMÉ}

Contexte : Le suivi thérapeutique pharmacologique est utile dans les cas où un médicament possède un indice thérapeutique étroit, si une posologie ne permet pas d'établir de façon fiable les concentrations sériques ou si les concentrations sériques d'un médicament ont une valeur de substitution (c'est-à-dire qu'elles reflètent les résultats cliniques). Le suivi thérapeutique pharmacologique est particulièrement important pour la population pédiatrique, où il existe une grande variabilité pharmacocinétique et des différences quant à la composition corporelle et au devenir des médicaments dans l'organisme. Malheureusement, on ne connaît que peu de choses à propos des habitudes de suivi thérapeutique pharmacologique de l'enfant et des facteurs qui influencent la prescription d'examens mesurant les concentrations sériques des médicaments.

Objectifs : Offrir un portrait des habitudes de suivi thérapeutique pharmacologique de la population pédiatrique au Canada, faire un compte rendu des médicaments qui nécessitent un suivi et la manière dont se déroule cette surveillance et déceler les facteurs qui influencent les habitudes de suivi thérapeutique pharmacologique de l'enfant.

Méthodes : Un sondage électronique a été mis au point à l'aide d'un logiciel de sondage en ligne puis envoyé à 42 centres de soins pédiatriques au Canada de janvier à mars 2016.

Résultats : Vingt (48\%) des 42 établissements interrogés ont répondu au sondage. Tous les établissements ont indiqué réaliser des suivis thérapeutiques pharmacologiques auprès de la population pédiatrique et le nombre médian de médicaments nécessitant une surveillance était de 18,5 (écart de 9 à 28) par établissement. Les établissements présentaient des différences en ce qui a trait aux habitudes de suivi thérapeutique pharmacologique (comme les indications pour les suivis thérapeutiques pharmacologiques et les types de mesures sériques de médicaments). À ce jour, les examens pharmacogénétiques ne jouent pas un rôle important dans le suivi thérapeutique pharmacologique. Selon les répondants, des éléments faisaient obstacle à la réalisation du suivi thérapeutique pharmacologique, notamment la croyance que certains médicaments n’ont pas de valeur clinique, l'accès limité à des tests diagnostiques et les retards dans l'obtention des résultats d'examen.

Conclusions : La réalisation du suivi thérapeutique pharmacologique est répandue au Canada. Afin de l'exercer de façon plus optimale dans le cadre de la pratique clinique, le personnel de la santé doit être davantage sensibilisé à la valeur clinique du suivi thérapeutique pharmacologique et il est nécessaire d'améliorer la rapidité d'accès aux résultats de ce suivi.

Mots clés : suivi thérapeutique pharmacologique, pédiatrie, sondage, Canada, hôpital 


\section{INTRODUCTION}

$\mathrm{T}$ herapeutic drug monitoring (TDM) is the clinical practice of measuring drug concentrations in the blood to optimize drug dosage regimens. It is helpful in situations where a drug has a narrow therapeutic index, a drug dosage does not reliably predict serum concentration, or a serum drug concentration has surrogate value. It may also be warranted in situations where there is large variation in pharmacokinetic parameters between different patients or within the same patient, because of differences or changes in kidney or liver function, volume status, body composition, or age. For drugs that meet the above-mentioned criteria, TDM is indicated on a clinical basis when a new regimen is started, a dosage is changed, or the serum drug concentrations are changing, either because of changes in a patient's clinical status or because interacting medications have been started or discontinued. ${ }^{1}$

In Canada, TDM is common practice and is recognized as being especially important for the pediatric population, because children's developmental physiology and differences in body composition lead to wide variability in pharmacokinetics, which may in turn affect the relation between dose and serum concentration. In addition to assisting with ensuring appropriate serum concentrations for effectiveness, TDM may be helpful in evaluating drug safety, as children may not be able to communicate effectively when they are experiencing adverse drug effects. However, children (especially neonates) are known to have lower total blood volumes, and blood sampling can contribute to anemia. Moreover, the relation between a drug's serum concentration and its effectiveness and safety is not well established for all medications for which TDM may be done. ${ }^{2}$ As such, clinicians should utilize TDM only when it is clinically helpful and only in the context of clinical assessment of the patient. Indeed, there are instances when it may be more appropriate to treat the patient on the basis of clinical status rather than solely on the basis of drug concentration. For example, if a patient who is taking an antiepileptic medication is well and seizure-free, dose changes may not be warranted, even if the serum drug concentration is below or above the standard target therapeutic range for that drug. The benefit of TDM in pediatrics was reported by the Hospital for Sick Children in Toronto, Ontario, where initiation of a TDM consultation service resulted in a reduction in the percentage of supratherapeutic drug concentrations $(4.25 \%$ before service initiation versus $2.25 \%$ after; $p<0.01) .^{3}$

Although TDM has been reported to be beneficial in pediatric practice, its use has not been well described. To our knowledge, no study attempting to characterize TDM practice for pediatric patients in general has been published. Moreover, TDM practice in Canada is poorly described, although nationwide surveys from other countries (e.g., United States, Australia, China, Malaysia, and Saudi Arabia ${ }^{4-8}$ ) exist. In Canada, results from a recent survey aiming to characterize vancomycin TDM practice for pediatric patients revealed significant variations among pediatric hospitals, ${ }^{3}$ which raises the possibility of wide variations in general pediatric TDM practice.

The purpose of this study was to describe current pediatric TDM practice in Canada. Specifically, this study aimed to describe what drugs are being monitored and how they are being monitored. Secondarily, this study also aimed to investigate whether other factors (e.g., characteristics of pediatric programs, availability of laboratory testing, training of pharmacists) affected pediatric TDM practice.

\section{METHODS}

\section{Distribution List for Survey}

Survey participants were clinical coordinators, pharmacy managers, or their delegates, representing Canadian health care centres identified through the Canadian Association of Paediatric Health Centres and investigator contacts. Each health care centre was first contacted by telephone to determine whether it fit the criteria of serving pediatric patients (age 0-18 years) and performing TDM (i.e., ordering measurement of serum drug concentrations). If both criteria were met, an invitation to participate in the survey was sent by e-mail. Participants were asked to disclose the name of the site for which they were responding, to control for instances of multiple responses from a single site (in which case their responses were to be compared and averaged). However, the data were de-identified and aggregated for analysis.

\section{Survey}

An English-language survey was developed using the online survey software FluidSurveys (Chide it, Inc) (see Appendix 1, available from https://www.cjhp-online.ca/index.php/cjhp/issue/ view/189/showToc). Face validity was determined by a clinical pharmacist who was not involved in the study but who had expertise in both survey methodology and TDM. Following receipt of approval from the institutional ethics review board, the survey was distributed electronically to participants on the distribution list. The online survey was available for completion from January 12 to March 8, 2016. The survey consisted of 2 parts. The first part contained questions relating to general TDM practice, including characteristics of the responding institution, pharmacy involvement in TDM, types of drugs monitored, barriers to TDM, indications for TDM, types of drug levels measured, and genotypic testing for TDM. The questions included in the survey were based on existing literature. ${ }^{4-8}$ Specific drugs listed in the survey were based on previous studies ${ }^{4-8}$ and TDM lists from our institutional chemistry laboratory. Although genotypic testing is not routinely performed for TDM, the survey included a question about pharmacogenomics, in light of expanding developments in gene research and the increasing availability of genotypic testing that could influence future TDM. The second 
part of the survey asked questions about the total number of drug serum measurements ordered per site in a typical month, as well as the location where TDM analytical tests were done. During the 2-month response period, a total of 3 reminders were sent, at 2-week intervals. No incentives were offered for completing this survey.

Participants were not required to complete both parts of the survey, but responses that were less than $50 \%$ complete were excluded from data analysis.

\section{Data Analysis}

Statistical analysis was performed with the IBM SPSS Statistics Premium GradPack program (version 22.0). Continuous outcomes based on 2 comparators (e.g., stand-alone pediatric hospital versus pediatric ward/service within an adult centre, teaching hospital versus nonteaching hospital, pharmacists able or unable to independently order serum drug measurements) were analyzed using the Student $t$ test if parametric or the MannWhitney $U$ test if nonparametric. For outcomes with multiple (> 2) comparators (e.g., pharmacy model: drug distribution centred, clinical practice centred, separate distribution and clinical practice, integrated distribution and clinical practice), analysis of variance was used when the outcomes were parametric, and the Kruskal-Wallis statistic when the outcomes were nonparametric. Linear regression analysis was performed to investigate whether increasing pharmacy involvement, pharmacist education, number of beds in the hospital, or availability of on-site TDM testing correlated with higher number of drugs monitored per site. Pharmacy involvement was measured as the summative number of all pharmacist-related TDM activities performed at the institution, specifically, ordering measurement of drug levels, interpreting results and modifying drug therapy accordingly, documenting TDM intervention in patient charts, or other. Each activity was weighted equally. Pharmacist education was measured as the summative number of all TDM training opportunities at each site, specifically, entry-to-practice degree curriculum, residency training curriculum, education modules "on the job", on-the-spot learning, or other. Each training opportunity was weighted equally.

\section{RESULTS}

Of 45 sites contacted initially, a total of 42 sites met both criteria, and 47 e-mail contacts were received from potential participants. Forty-seven surveys were then distributed to the 42 sites by email. Twenty-two survey responses were received, but 2 of these did not meet the minimum $50 \%$ completion criterion and thus were excluded (survey completion rate 91\%). No site reported more than once, so averaging of results was not required. Ultimately, 20 responses were used for data analysis (48\% of all sites that met the original criteria). Seven (70\%) of the 10 Canadian pediatric hospitals and $13(41 \%)$ of the 32 pediatric/ward services in Canada participated in this survey (Table 1).

From a list of 30 drugs for which measurement of serum concentration is commonly ordered, respondents were asked to select those that were monitored at their site. Overall, the median number of drugs monitored per site was 18.5 (range 9-28). For the 7 pediatric hospitals, the median number of drugs monitored was 19 (range 16-28), and for pediatric wards within adult centres the median was 18 (range 9-25). The most commonly monitored drugs (i.e., TDM reported by $\geq 80 \%$ of sites) were antibiotics (aminoglycosides, vancomycin), antiepileptics (phenobarbital, phenytoin, carbamazepine, valproic acid), lithium, immunosuppressants (cyclosporine, tacrolimus), digoxin, and theophylline/ aminophylline (Table 2). Unfortunately, only 3 sites submitted data for the total number of serum drug measurements ordered at their site in a typical month (for part II of the study), which was insufficient for any meaningful interpretation.

Respondents were asked to select from a list of 6 potential barriers to TDM for the medications not monitored at their sites. The most common reasons for not monitoring certain medications (from the list of 30 medications included in the survey) were perceived lack of clinical value, poor access to analytical tests, and time delay to receipt of test results (Table 3).

For the commonly monitored drugs and drug classes (e.g., aminoglycosides, vancomycin, antiepileptics, and immunosuppressants), the indications for ordering serum drug measurements are listed in Table 4. The most common reasons reported were clinical changes to a patient's status, changes to a patient's renal or hepatic function, or initiation of the medication.

The reported timing of sampling for measurement of serum drug concentrations, relative to dose administration, is presented in Table 5. For a substantial proportion of responses, the timing of sampling was reported as "random" or "other", which included responses such as " $8 \mathrm{hr}$ post dose using Hartford Nomogram", " $3 \mathrm{hr}$ and $6 \mathrm{hr}$ post dose levels (routine)" for aminoglycosides (extended), "post-load level for patients in status epilepticus" for antiepileptics, and area under the curve (AUC) for immunosuppressants.

Of the factors determining whether TDM was performed (Table 6), availability of on-site analytical testing was the only one that was statistically significant $\left(R^{2}=0.683, p<0.001\right)$.

Of the 20 sites that responded to the survey, 6 sites (30\%) reported performing pharmacogenetic testing, but such testing was not part of TDM at any of these sites. Only 3 of the 6 sites that reported pharmacogenetic testing provided examples of the tests performed. All 3 of these sites performed genetic testing for thiopurine methyltransferase before initiation of a thiopurine drug; in addition, one site reported testing of the HLA-B*1502 allele (for carbamazepine) and HLA-B*5701 (for abacavir). Two sites indicated that they were in the process of improving the availability of these tests for their sites. 
Table 1. Characteristics of Canadian Hospitals Responding to a Survey of Therapeutic Drug Monitoring

\begin{tabular}{|c|c|c|c|}
\hline \multirow{2}{*}{$\begin{array}{l}\text { Characteristic } \\
\text { Province }\end{array}$} & \multicolumn{3}{|c|}{$\begin{array}{c}\text { No. }(\%) \text { of } \\
\text { Respondents* }(n=20)\end{array}$} \\
\hline & & & \\
\hline British Columbia & & 4 & (20) \\
\hline Alberta & & 3 & (15) \\
\hline Saskatchewan & & 1 & (5) \\
\hline Ontario & & 8 & (40) \\
\hline Quebec & & 2 & (10) \\
\hline Nova Scotia & & 1 & (5) \\
\hline Prince Edward Island & & 1 & (5) \\
\hline \multicolumn{4}{|l|}{ Pediatric setting } \\
\hline Pediatric hospital & & 7 & (35) \\
\hline Pediatric ward/service & & 13 & (65) \\
\hline \multicolumn{4}{|l|}{ University affiliation } \\
\hline Yes & & & (90) \\
\hline No & & 2 & (10) \\
\hline Hospital size & Total Bedst & & liatric beds $\ddagger$ \\
\hline$<50$ beds & 0 & & 8 \\
\hline $50-200$ beds & 4 & & 9 \\
\hline $201-500$ beds & 11 & & 3 \\
\hline$>500$ beds & 4 & & 0 \\
\hline Unknown & 1 & & 0 \\
\hline No. of beds (median and IQR) & $425(230-450)$ & & $15(22-161)$ \\
\hline \multicolumn{4}{|c|}{$\begin{array}{l}\text { IQR = interquartile range. } \\
\text { *Except where indicated otherwise. } \\
\text { tData in this column represent the number of institutions in each category, based on } \\
\text { the total number of beds in each insitution. } \\
\text { fData in this column represent the number of insitutions with pediatric beds in each } \\
\text { category, whether the institution was a pediatric hospital or a hospital serving } \\
\text { patients of any age with some dedicated pediatric beds. For example, there were } \\
\text { no hospitals with total number of beds less than } 50 \text {, but } 8 \text { hospitals had dedicated } \\
\text { pediatric beds that numbered fewer than } 50 \text {. Conversely, there were } 4 \text { hospitals } \\
\text { with more than } 500 \text { beds in total, but no hospitals had more than } 500 \text { dedicated } \\
\text { pediatric beds. }\end{array}$} \\
\hline
\end{tabular}

\section{DISCUSSION}

In this study, we found that TDM services are widely available for monitoring drug therapy in pediatric patients in health care centres across Canada, a result that is consistent with TDM surveys conducted in other countries. ${ }^{4-8}$ All respondents indicated that they provide TDM services for pediatric patients. Our study provides data from 7 provinces across Canada, and captures information for $70 \%$ of the 10 Canadian pediatric hospitals. No information was available for Nunavut, Northwest Territories, Yukon, Manitoba, New Brunswick, or Newfoundland and Labrador.

We found that TDM was not widely available for many drugs (with TDM being reported for a median of 18.5 drugs out of 30 listed in the survey); however, those drugs that were commonly monitored were monitored by many sites (e.g., 16 of the frequently monitored drugs were monitored by $\geq 80 \%$ of all sites). It appears that the most common reasons for ordering measurement of serum drug levels were the initiation of new medications, changes in a patient's clinical status, or changes to a patient's renal or hepatic function. It is thus interesting to note that the addition or discontinuation of an interacting drug was not a common reason to order measurement of serum drug concentrations, although the effect of an interacting medication on the concentrations of other drugs may be comparable to effects related to changes in a patient's renal or hepatic function. Nevertheless, for medications that are more often used in the management of chronic diseases (e.g., antiepileptics for epilepsy, immunosuppressants for organ transplant or cancer), it does appear that the addition or discontinuation of an interacting medication prompted more frequent ordering of serum drug measurement (about $80 \%$ of the time).

The findings for the types of serum drug measurement ordered were interesting. Thirty percent of sites monitored peak concentrations for aminoglycosides (extended-interval dosing), whereas monitoring only the trough or random concentration is considered the norm. ${ }^{9}$ We found that only $25 \%$ of sites monitored peak vancomycin concentrations, which was not surprising, considering that Delicourt and others ${ }^{10}$ found previously that Canadian hospitals monitored peak vancomycin concentrations for only about $10 \%$ of their patients. Monitoring peak vancomycin concentration is currently controversial in pediatric pharmacotherapy practice, and there are variations in practice across the country and internationally. Finally, a remarkable proportion of responses regarding the types of serum drug 
This single copy is for your personal, non-commercial use only.

For permission to reprint multiple copies or to order presentation-ready copies for distribution, contact CJHP at publications@cshp.ca

Table 2. Monitored Drugs and Location of Analytical Testing

\begin{tabular}{|c|c|c|c|c|c|c|c|}
\hline \multirow[t]{2}{*}{ Drug } & \multirow{2}{*}{\multicolumn{2}{|c|}{$\begin{array}{l}\text { No. }(\%) \text { of } \\
\text { Hospitals } \\
\text { Monitoring } \\
(n=20)\end{array}$}} & \multicolumn{5}{|c|}{ Test Location; \% of Hospitals* } \\
\hline & & & $\begin{array}{l}\text { On } \\
\text { Site }\end{array}$ & $\begin{array}{c}\text { Within } \\
\text { Same City }\end{array}$ & $\begin{array}{l}\text { Within } \\
\text { Province }\end{array}$ & $\begin{array}{l}\text { Within } \\
\text { Country }\end{array}$ & $\begin{array}{l}\text { Outside } \\
\text { Country }\end{array}$ \\
\hline \multicolumn{8}{|l|}{ Antibiotics } \\
\hline Amikacin, extended-interval dosing & 17 & $(85)$ & 38 & 31 & 31 & 0 & 0 \\
\hline Amikacin, traditional dosing & & (95) & 38 & 31 & 31 & 0 & 0 \\
\hline Gentamicin, extended-interval dosing & & (95) & 85 & 15 & 0 & 0 & 0 \\
\hline Gentamicin, traditional dosing & & $(100)$ & 79 & 21 & 0 & 0 & 0 \\
\hline Tobramycin, extended-interval dosing & & $(90)$ & 85 & 15 & 0 & 0 & 0 \\
\hline Tobramycin, traditional dosing & & (95) & 79 & 21 & 0 & 0 & 0 \\
\hline Vancomycin & & $(100)$ & 93 & 7 & 0 & 0 & 0 \\
\hline \multicolumn{8}{|l|}{ Antiepileptics } \\
\hline Carbamazapine & 19 & (95) & 85 & 15 & 0 & 0 & 0 \\
\hline Ethosuximide & 8 & $(40)$ & 29 & 29 & 29 & 0 & 14 \\
\hline Phenobarbital & 20 & $(100)$ & 77 & 8 & 15 & 0 & 0 \\
\hline Phenytoin & 20 & $(100)$ & 92 & 8 & 0 & 0 & 0 \\
\hline Valproic acid & 20 & $(100)$ & 85 & 15 & 0 & 0 & 0 \\
\hline \multicolumn{8}{|l|}{ Antipsychotics, antidepressants } \\
\hline Clozapine & 7 & (35) & 57 & 29 & 14 & 0 & 0 \\
\hline Imipramine & 2 & $(10)$ & 20 & 20 & 60 & 0 & 0 \\
\hline Lithium & 18 & (90) & 67 & 25 & 8 & 0 & 0 \\
\hline \multicolumn{8}{|l|}{ Immunosuppressants } \\
\hline Cyclosporine & 18 & (90) & 67 & 25 & 8 & 0 & 0 \\
\hline Sirolimus & 11 & (55) & 50 & 25 & 25 & 0 & 0 \\
\hline Tacrolimus & 16 & (80) & 60 & 30 & 10 & 0 & 0 \\
\hline \multicolumn{8}{|l|}{ Antiarrhythmics } \\
\hline Digoxin & 19 & (95) & 75 & 25 & 0 & 0 & 0 \\
\hline Disopyramide & 3 & (15) & 0 & 17 & 50 & 17 & 17 \\
\hline Lidocaine & 4 & (20) & 14 & 14 & 43 & 29 & 0 \\
\hline N-Acetylprocainamide & 2 & (10) & 0 & 14 & 57 & 29 & 0 \\
\hline Procainamide & 3 & $(15)$ & 0 & 14 & 57 & 29 & 0 \\
\hline Propranolol & 2 & (10) & 33 & 33 & 33 & 0 & 0 \\
\hline Quinidine & 4 & (20) & 14 & 14 & 43 & 29 & 0 \\
\hline \multicolumn{8}{|l|}{ Other } \\
\hline Acetaminophen & 2 & (10) & 90 & 10 & 0 & 0 & 0 \\
\hline Caffeine & 7 & (35) & 67 & 0 & 22 & 0 & 11 \\
\hline Methotrexate & 12 & (60) & 80 & 10 & 10 & 0 & 0 \\
\hline Salicylate (acetylsalicylic acid) & 6 & (30) & 67 & 33 & 0 & 0 & 0 \\
\hline Theophylline/aminophylline & 17 & (85) & 58 & 33 & 8 & 0 & 0 \\
\hline
\end{tabular}

*Percentages based on number of hospitals performing monitoring for each particular drug.

Table 3. Reported Barriers to Therapeutic Drug Monitoring (TDM)

\begin{tabular}{lrr} 
Barrier & No. (\%) of Hospitals \\
& \multicolumn{2}{c}{$(\boldsymbol{n}=\mathbf{2 0 )}$} \\
\hline Perceived lack of clinical value & 16 & $(80)$ \\
Poor access to analytical tests & 10 & $(50)$ \\
Time delay to test results & 8 & $(40)$ \\
Limited TDM operating hours & 2 & $(10)$ \\
Lack of training & 1 & $(5)$ \\
Technical difficulties in retrieving sufficient sample & 0 & $(0)$ \\
from patient & & \\
\hline
\end{tabular}

measurements ordered were described as "other" (e.g., up to 16\% for certain drugs/drug categories). This suggests potential unique variations in practice that this survey may not have been able to fully capture.
The main reported barriers to TDM were perceived lack of clinical value for the drugs that were not monitored, followed by poor access to analytical tests and time delay to receiving test results. We were not surprised to learn that perceived lack of 
clinical value was the greatest barrier to TDM (reported by $80 \%$ of respondents). Although helpful in monitoring drug efficacy and safety, TDM may be considered redundant when there are other objective, overt patient signs and symptoms or laboratory markers that can be used to monitor therapy. Clinicians are often told to treat the patient, not the levels, and this principle is reflected in the survey results. Given the low blood volumes available in children, it appears that TDM tests are not ordered except when deemed to be clinically helpful, examples of which are highlighted in Table 4 for some of the commonly monitored medications. With regard to the barrier of poor access, we also found that drugs were monitored less frequently when sites did not have on-site analytical testing available $\left(R^{2}=0.683\right.$, $p<0.001)$. It is evident, then, that the availability of analytical testing is a barrier to optimal TDM practice. The results of this survey also suggest that TDM might be used more often if the timeliness of receiving test results could be improved, as the results would be more applicable to informed decision-making.
This survey study had several limitations, the main one being that certain adult centres that also serve pediatric patients may have experienced difficulty in answering the survey questions, because TDM practice may be different for pediatric and adult patients, and the survey did not specifically address these differences. However, in our analysis of potential differences between pediatric hospitals and pediatric wards in adult centres (where confounding may exist), we did not detect any significant differences ( $p=0.48$ ), although this may have been a result of the small sample size. Also, responses may vary from one pharmacist to another at the same site (depending on past work experiences, work culture, etc.), and the survey sought responses from only one pharmacist at each site. By contacting the clinical coordinator/pharmacy manager at each site, we hoped to minimize this variability and to get a general picture of TDM practices at each specific site. Finally, a majority (40\%) of the data came from Ontario sites.

Table 4. Indications for Therapeutic Drug Monitoring (TDM) $(n=20)$

\begin{tabular}{|c|c|c|c|c|c|c|c|c|c|c|c|c|}
\hline \multirow{3}{*}{$\begin{array}{l}\text { Type of Drug } \\
\text { Aminoglycosides, extended-interval } \\
\text { dosing }\end{array}$} & \multicolumn{10}{|c|}{ Indication for TDM; No. (\%) of Respondents* } & \multirow{2}{*}{\multicolumn{2}{|c|}{ Unknown }} \\
\hline & \multicolumn{2}{|c|}{$\begin{array}{l}\text { Initiation of } \\
\text { Medication }\end{array}$} & \multicolumn{2}{|c|}{$\begin{array}{l}\text { Clinical } \\
\text { Changes }\end{array}$} & \multicolumn{2}{|c|}{$\begin{array}{l}\text { Changes in } \\
\text { Renal or } \\
\text { Hepatic } \\
\text { Function } \\
\end{array}$} & \multicolumn{2}{|c|}{$\begin{array}{c}\text { Adding or } \\
\text { Discontinuing } \\
\text { an Interacting } \\
\text { Medication }\end{array}$} & \multicolumn{2}{|c|}{$\begin{array}{l}\text { Does Not } \\
\text { Monitor } \\
\text { This Drug }\end{array}$} & & \\
\hline & 15 & (75) & 16 & $(80)$ & 17 & (85) & 10 & $(50)$ & 1 & (5) & 1 & (5) \\
\hline Aminoglycosides, traditional dosing & 17 & (85) & 18 & (90) & 18 & (90) & 11 & $(55)$ & 1 & (5) & 1 & (5) \\
\hline Antiepileptics & 16 & (80) & 18 & (90) & 13 & (65) & 16 & (80) & 0 & (0) & 1 & (5) \\
\hline Immunosuppressants & 14 & (70) & 15 & (75) & 14 & (70) & 13 & (65) & 1 & (5) & 4 & (20) \\
\hline Vancomycin & 17 & (85) & 18 & (90) & 18 & (90) & 11 & (55) & 0 & (0) & 1 & \\
\hline
\end{tabular}

*For each medication, a given institution responding to the survey could have multiple indications for performance of TDM.

Table 5. Types of Serum Drug Measurements $(n=20)$

\begin{tabular}{|c|c|c|c|c|c|c|c|c|c|c|}
\hline \multirow{3}{*}{$\begin{array}{l}\text { Type of Drug } \\
\text { Aminoglycosides, } \\
\text { extended-interval dosing }\end{array}$} & \multicolumn{10}{|c|}{ Type of Measurement; No. (\%) of Respondents } \\
\hline & \multicolumn{2}{|c|}{ Peak } & \multicolumn{2}{|c|}{ Trough } & \multicolumn{2}{|c|}{ Random } & \multicolumn{2}{|c|}{ Other } & \multicolumn{2}{|c|}{ Unknown } \\
\hline & & (30) & 17 & (85) & 7 & (35) & 3 & (15) & 0 & (0) \\
\hline $\begin{array}{l}\text { Aminoglycosides, } \\
\text { traditional dosing }\end{array}$ & 17 & (85) & 19 & (95) & 4 & $(20)$ & 0 & (0) & 0 & (0) \\
\hline Antiepileptics & 0 & (0) & 19 & (95) & 4 & (20) & 1 & (5) & 1 & (5) \\
\hline Immunosuppressants & 0 & (0) & 15 & (75) & 1 & (5) & 3 & (15) & 1 & (5) \\
\hline Vancomycin & 5 & (25) & 20 & (100) & 7 & (35) & 0 & (0) & 0 & (0) \\
\hline
\end{tabular}

Table 6. Factors Potentially Affecting Pediatric Therapeutic Drug Monitoring (TDM)

\begin{tabular}{llc} 
Factor & Statistical Test & $\boldsymbol{p}$ Value \\
\hline Stand-alone pediatric hospital versus pediatric ward/ & Mann Whitney $U$ & 0.48 \\
service in adult centre & Mann Whitney $U$ & 0.06 \\
University affiliation & Mann Whitney $U$ & 0.52 \\
Ability of pharmacist to independently order TDM & Linear regression & 0.15 \\
Extent of pharmacist training & Kruskal-Wallis & 0.57 \\
Pharmacy practice model & Linear regression & 0.65 \\
Extent of pharmacist involvement & Linear regression & 0.06 \\
Number of beds & Linear regression & $<0.001$ \\
Availability of on-site analytical test &
\end{tabular}


This single copy is for your personal, non-commercial use only.

For permission to reprint multiple copies or to order presentation-ready copies for distribution, contact CJHP at publications@cshp.ca

\section{CONCLUSION}

TDM for pediatric patients is accessible and available in many pediatric health care programs in Canada, but differences exist in terms of the types of drugs monitored, when they are monitored, and how they are monitored. Pharmacogenetic testing is not widely available to many sites and is not currently used in TDM; however, efforts to improve the availability of pharmacogenetic testing for TDM are underway at several institutions. Currently, the most important reason for not routinely monitoring certain drugs in pediatrics is perceived lack of clinical value; further investigation into the reasons for this perception may be warranted, given that the current survey was not designed to specifically address this issue. However, it is recognized that barriers to optimal TDM practice also include the availability and timeliness of TDM test results.

\section{References}

1. Soldin OP, Soldin SJ. Review: therapeutic drug monitoring in pediatrics. Ther Drug Monit. 2002;24(1):1-8.

2. Kang J, Lee M. Overview of therapeutic drug monitoring. Korean J Intern Med. 2009;24(1):1-10.

3. Koren G, Soldin SJ, MacLeod SM. Organization and efficacy of a therapeutic drug monitoring consultation service in a pediatric hospital. Ther Drug Monit. 1985;7(3):295-8.

4. Murphy JE, Slack MK, Campbell S. National survey of hospital-based pharmacokinetic services. Am J Health Syst Pharm. 1996;53(23):2840-7.

5. Norris RL, Martin JH, Thompson E, Ray JE, Fullinfaw RO, Joyce D, et al. Current status of therapeutic drug monitoring in Australia and New Zealand: a need for improved assay evaluation, best practice guidelines, and professional development. Ther Drug Monit. 2010;32(5):615-23.

6. Guo W, Guo GX, Sun C, Zhang J, Rong Z, He J, et al. Therapeutic drug monitoring of psychotropic drugs in China: a nationwide survey. Ther Drug Monit. 2013;35(6):816-22.

7. Ab Rahman AF, Ahmed Abdelrahim HE, Mohamed Ibrahim MI. A survey of therapeutic drug monitoring services in Malaysia. Saudi Pharm J. 2013;21(1):19-24.

8. Alsultan MS, Mayet AY, Khurshid F, Al-jedai AH. Hospital pharmacy practice in Saudi Arabia: drug monitoring and patient education in the Riyadh region. Saudi Pharm J. 2013;21(4):361-70.
9. Davis GA, editor. Clinical pharmacokinetics service \& anticoagulation guidelines. Lexington (KY): University of Kentucky, UK HealthCare, Pharmacy Services; [revised 2017 Jan; cited 2019 Mar 18]. Available from: https://ukhealthcare.uky.edu/sites/default/files/clinical-pks-anticoagulationmanual.pdf

10. Delicourt A, Bussières JF, Lebel D. Pediatric pharmacokinetics of vancomycin: a Canadian perspective. Can J Hosp Pharm. 2011;64(2):156-7.

Donna Leung, BSc(Hons), BSc(Pharm), ACPR, was, at the time of writing, a Pharmacy Resident, Lower Mainland Pharmacy Services and Faculty of Pharmaceutical Sciences, The University of British Columbia, Vancouver, British Columbia. She is now a Clinical Pharmacist, Department of Pharmacy, Children's \& Women's Health Centre of British Columbia, Vancouver, British Columbia.

Mary H H Ensom, BS(Pharm), PharmD, FASHP, FCCP, FCSHP, was, at the time of writing, a Professor, Faculty of Pharmaceutical Sciences, and Distinguished University Scholar, The University of British Columbia; a Clinical Pharmacy Specialist, Children's \& Women's Health Centre of British Columbia; and Senior Associate Clinician Scientist, Child \& Family Research Institute, Vancouver, British Columbia. She has since retired and is now Professor Emerita, Faculty of Pharmaceutical Sciences, The University of British Columbia.

Roxane Carr, BSC, BSc(Pharm), ACPR, PharmD, BCPS, FCSHP, is Clinical Coordinator, Department of Pharmacy, Children's \& Women's Health Centre of British Columbia, and Assistant Professor, Part-time, Faculty of Pharmaceutical Sciences, The University of British Columbia, Vancouver, British Columbia.

Competing interests: None declared.

\section{Address correspondence to:}

Dr Roxane Carr

Department of Pharmacy, Room OB7

BC Children's Hospital

4480 Oak Street

Vancouver BC V6H 3N1

e-mail: rcarr2@cw.bc.ca

Funding: None received.

Acknowledgement: The authors would like to thank Dr Jennifer Kendrick, Clinical Pharmacy Specialist, for reviewing the questionnaire developed in this study before its dissemination. 